Author's reply: I did not mean to suggest that a mother is always certain of the paternity of her offspring - merely that she is certain that her offspring perpetuate her genes, while a father can never be similarly sure that his genes are perpetuated in the offspring of his sexual partners. Hence, it is suggested that each gender faced distinct reproductive problems that required different adaptive solutions.

I am indeed aware of the long-time opponents of evolutionary psychology that Lucas refers to. Most (e.g. Rose \& Rose and Lewontin) are evolutionary biologists who are prepared to accept that physical organs (e.g. the eye or the hand) have been designed by selection but draw the line at the human psyche or mind. Their antipathy to any suggestion that the human mind may have any architecture whatsoever that could have been shaped by the evolutionary process places them effectively in the camp that views the mind as a tabula rasa.

Moreover, Lucas is quite mistaken in suggesting that evolutionary psychology is biologically deterministic. Biological determinism is simply wrong and you will find every book or chapter on the subject stressing this fact (see Buss, 1999; Thornhill \& Palmer, 2000). Unlike the narrow (nonevolutionary) biological view, evolutionary psychology accepts that all traits are the result of the interaction of genes and the environment. However, the difference between this view and that of the 'standard social science model' (Tooby \& Cosmides, 1992; Gaulin \& McBurney, 2001) is that traits are not considered to be endlessly malleable. Some traits are fixed through a wide range of environmental conditions (obligate traits; e.g. having two eyes), while others are highly sensitive to environmental change (facultative traits; e.g. degree of tanning of the skin or the propensity to violence). Nevertheless, even obligate traits can be disrupted as a result of environmental factors at critical developmental stages.

Evolutionary psychology has no problem accepting complexity and contrary to Lucas does not consider the brain or any other human organ to be optimally designed. Evolution produces its effect quite often through compromise and through building on what already exists. The design of the human throat that creates the propensity to choke each time we swallow due to the passage of all the food precariously over the wind-pipe is a case in point. Nor is it denied that factors other than selection, such as drift and mutation, influence the frequency of traits in a given population. However, only selection is capable of producing adaptations - the domain-specific, highly specialised traits or organs that perform a survival or reproductive function for the organism and contribute directly to its inclusive fitness (see Williams, 1966). Hence, whereas the colour of blood may be the result of drift, the design of the lens in the human eye can only have been the result of selection.

Lucas alludes more than once to the excesses of 'eugenics' and 'social Darwinism'. No doubt social Darwinism was bad science and an abuse of Darwinism. Evolutionary psychology, by contrast, is a hypothesis-driven empirical science and not a political ideology. This does not mean it cannot be abused or distorted but science cannot be blamed for its abuse by the unscrupulous. It is also worth remembering that the excesses of extreme 'environmentalism' (a trend still quite influential and prevalent in various quarters) were no less gruesome and led to the death of millions of people in Stalinist Russia and elsewhere all in the name of creating the new citizens (through re-education and indoctrination).

Finally, Prothero is right to point out that sciences other than psychiatry tolerate a degree of conceptual pluralism. However, I would contend that the pluralism in physics has stimulated considerable theoretical and experimental work to resolve the inconsistencies generated by mutually exclusive theories. Can we say the same about psychiatry?

Buss, D. (1999) Evolutionary Psychology: The New Science of the Mind. Boston, MA: Allen and Bacon.

Gaulin, S. J. C. \& McBurney, D. H. (200I) Psychology An Evolutionary Approach. Upper Saddle River, NJ: Prentice Hall.

Thornhill, R. \& Palmer, C. (2000) A Natural History of Rape: Biological Basis of Sexual Coercion. Cambridge, MA MIT Press.

Tooby, J. \& Cosmides, L. (1992) The psychological foundations of culture. In The Adapted Mind: Evolutionary Psychology and the Generation of Culture (eds J. $\mathrm{H}$. Barkow, L. Cosmides \& J. Tooby), pp 19-136. New York: Oxford University Press.

Williams, G. (1966) Adaptation and Natural Selection. Princeton, NJ: Princeton University Press.

R.T. Abed Rotherham District General Hospital Rotherham S60 2UD

\section{Psychotropic drugs and sudden death}

In their editorial, Appleby et al (2000) indicated that the mechanism of sudden death among patients taking antipsychotic medications might be ventricular arrhythmias and that QTc prolongation might be a particularly important harbinger of these events.

Another electrocardiographic sign (without prolonged QTc) that may be associated with sudden death from ventricular fibrillation is the Brugada sign (i.e. right bundle branch block and elevation of the ST segment; Brugada \& Brugada, 1992). Buckley \& Sanders (2000) have commented that although no specific antipsychotic has been directly associated with the Brugada sign (unlike the tricyclic antidepressants), antipsychotic medications with the capacity to block sodium channels may precipitate this and possibly lead to sudden death.

In addition to the risk factors mentioned, drug-drug interaction is an important consideration. Drugs like the tricyclic antidepressants and lithium, with their propensity to prolong the QT interval, may have a synergistic additive effect when combined with an antipsychotic medication. Inhibition of the cytochrome P450 enzymes involved in the metabolism of psychotropic drugs leads to increased blood levels, and prolongation of the QT interval in individuals taking antipsychotic medications such as haloperidol, sertindole, risperidone and olanzapine occurs in a concentrationrelated manner (Drici et al, 1998). Certain selective serotonin reuptake inhibitors (fluvoxamine, paroxetine) are potent inhibitors of some of these cytochrome P450 enzymes. Grapefruit juice, although seemingly innocuous, has attained some notoriety from its association with prolonged QT intervals in individuals taking terfenadine and has been implicated in one death (Jefferson, 1998). Grapefruit juice is a potent inhibitor of the P450 CYP1A2, 2A6 and 3A4 enzymes, which are important in the metabolism of clozapine, amitriptyline, imipramine and clomipramine. Clinicians should therefore be mindful of these interactions and give the appropriate warning to their patients taking these medications.

Appley, L., Thomas, S., Ferrier, N., et al (2000) Sudden unexplained death in psychiatric in-patients. British Journal of Psychiatry, 176, 405-406.

Brugada, P. \& Brugada, J. (1992) Right bundle branch block, persistent ST segment elevation and sudden cardiac death: a distinct clinical and electrocardiographic 
syndrome. A multicenter report. Journal of the American College of Cardiology, 20, 1391-1396.

Buckley, N. A. \& Sanders, P. (2000) Cardiovascular adverse effects of antipsychotic drugs. Drug Safety, 23, $215-228$

Drici, M. D., Wang, W. X., Liu X. E., et al (1998) Prolongation of QT interval in isolated feline hearts by antipsychotic drugs. Journal of Clinical Psychopharmacology, 18, 477-48I.

Jefferson, J.W. (1998) Drug and diet interactions avoiding therapeutics paralysis. Journal of Clinical Psychiatry, 59 (suppl. 16), 31-39.

S.-A. Chong Institute of Mental Health and Woodbridge Hospital, 10 Buangkok View, Singapore 539747, Singapore

\section{Cognitive-behavioural techniques in practice}

The randomised controlled trial reported by Turkington $\&$ Kingdon (2000) demonstrated therapeutic benefit from a general psychiatrist using cognitive-behavioural techniques with patients experiencing psychotic symptoms. However, the conclusion that "general psychiatrists could help their patients with schizophrenia by using cognitive-behavioural techniques" (p. 101) may not fully reflect the fact that the sole therapist in this study is an international expert in cognitive-behavioural therapy (CBT) with psychosis, who has co-written one of the seminal texts (Kingdon \& Turkington, 1994).

Lack of time is highlighted as the main difficulty for psychiatrists wanting to use CBT, but other limiting factors may include the knowledge, skills and attitudes of the psychiatrist. Experience as a clinical psychologist supervising trainee psychiatrists suggests that the knowledge base is not generally problematic-medical training equips practitioners with the ability to assimilate new information rapidly.

Skills development in CBT is more difficult. The difference between the Turkington \& Kingdon approach and cognitive therapy is that a formulation is not used, but it may be that an experienced CBT practitioner (as in their study) employs an implicit individualised formulation, whereas a more typical general psychiatrist would not. Cognitive-behavioural techniques can be powerful, and using these techniques without a formulation can be clinically dangerous. For example, undertaking attributional change in a patient with paranoia without regard for the link between persecutory delusions and selfesteem (Lyon et al, 1994) may trigger depression. Cognitive-behavioural skills development requires clinical supervision.

Attitudinal change is most difficult. Consider the response of a psychiatrist to a patient's question, "Should I take my medication?". Valid responses might include "Yes" from a biological psychiatrist, and "Here's the evidence of effectiveness ..." from a social psychiatrist. However, a response such as "How will you decide?" is a more appropriate cognitive-behavioural response. Psychiatrists can develop these alternative attitudes, but a 'psychiatric' mind-set often re-emerges in therapy.

Improved access for patients to psychological therapies is imperative. However, although it may serve the profession of psychiatry well to indicate that the use of CBT is easily within the grasp of all its practitioners, it is not clear that this is empirically demonstrated.

Kingdon, D. \& Turkington, D. (1994) CognitiveBehavioral Therapy of Schizophrenia. Hove: Lawrence Erlbaum.

Lyon, H. M., Kaney, S. \& Bentall, R. P. (1994) The defensive function of persecutory delusions. Evidence from attribution tasks. British journal of Psychiatry, 164 637-646.

Turkington, D. \& Kingdon, D. (2000) Cognitivebehavioural techniques for general psychiatrists in the management of patients with psychoses. British Journal of Psychiatry, I77, I01-106

M. Slade Health Services Research Department, Institute of Psychiatry, Denmark Hill, London SE5 8AF

Authors' reply: We thank Dr Slade for his interest in our paper and are grateful for the chance to clarify these crucial points. At the time this study was carried out D.K. was a general psychiatrist working full-time in the community. He did have a general cognitive therapy training and applied the techniques that he had learned for the treatment of depression and anxiety in an adapted form to his patients with schizophrenia (Kingdon \& Turkington, 1991). We then designed this study to test the efficacy of these techniques as against a befriending control (Kingdon et al, 1989). The study was then carried out in the course of D.K.'s clinical work.

We accept that a shared formulation is a fundamental component of cognitive therapy with schizophrenia (Fowler et al, 1995), which not only helps to direct the process of therapy but which can also help to predict the emergence of depression as a delusion recedes. The identification of key maladaptive core beliefs is part of the process of formulation and helps when there are blocks in progress and in the prevention of relapse. Psychiatrists do not normally identify such core beliefs in their case formulations and may not share all of the formulation with the patient. However, the formulations of psychiatrists do contain an aetiological component comprising such issues as genetic predisposition, birth traumas, early losses and personality. The precipitation of the psychosis in relation to any pertinent life events is included, as are maintaining factors such as isolation, poor adherence or high expressed emotion within the family (Gelder et al, 1983). Formulation is so central to psychiatric practice that it is a key component of the Royal College of Psychiatrists' membership examination. With such formulations psychiatrists can safely use cognitive-behavioural techniques as long as they remain aware of the risk of emerging depression or increased suicidal ideation linked to improved insight. Such phenomena are widely recognised in psychiatry when certain types of symptoms (e.g. grandiose or systematised delusions) respond to antipsychotic medication.

The purpose of our paper was to attempt to shift attitudes in psychiatry in order that we can be better engaged with our patients who have psychoses by working more directly with their symptoms rather than simply monitoring them and titrating antipsychotic medication. If general psychiatrists can make this shift in attitude, training workshops and supervision will be necessary. We expect that this shift could well facilitate the delivery of formal cognitive therapy by other community mental health teams trained in this approach and help with the implementation of other psychosocial interventions in this patient population.

Fowler, D., Garety, P. \& Kuipers, E. (1995) Cognitive Behaviour Therapy for Psychosis: Theory and Practice. The Wiley Series in Clinical Psychology. Chichester: John Wiley \& Sons.

Gelder, M., Gath, D. \& Mayou, R. (1983) Oxford Textbook of Psychiatry. Oxford: Oxford Medical.

Kingdon, D. G. \& Turkington, D. (1991) Preliminary report: the use of cognitive behaviour therapy and a normalizing rationale in schizophrenia. Journal of Nervous and Mental Disease, 179, 207-211.

$\ldots, \ldots$, Collis, J., et al (1989) Befriending: costeffective community care. Psychiatric Bulletin, I3, 350-35I.

D. Turkington, D. G. Kingdon Emergency Liaison Team, Leazes Wing, Royal Victoria Infirmary, Queen Victoria Road, Newcastle upon Tyne NEI 4LP 